\title{
Lung volume reduction surgery in the post-National Emphysema Treatment Trial era
}

\author{
B. Payne Stanifer, Mark E. Ginsburg
}

Section of Thoracic Surgery, Department of Surgery, Columbia University Medical Center, New York Presbyterian Hospital, New York, NY, USA Contributions: (I) Conception and design: All authors; (II) Administrative support: None; (III) Provision of study materials or patients: ME Ginsburg; (IV) Collection and assembly of data: All authors; (V) Data analysis and interpretation: All authors; (VI) Manuscript writing: All authors; (VII) Final approval of manuscript: All authors.

Correspondence to: B. Payne Stanifer, MD, MPH. Herbert Irving Pavilion, 161 Fort Washington Avenue, 3rd floor Room 333, New York, NY 10032, USA. Email: Bps2131@cumc.columbia.edu.

\begin{abstract}
Lung volume reduction surgery (LVRS) as means to improve the pulmonary function and quality of life of patients with chronic obstructive pulmonary disease (COPD) can be traced back to the 1950's and early work by Otto Brantigan. Joel Cooper revived this concept with pioneering work in the 1990's. His work, along with others, led to the National Emphysema Treatment Trial (NETT) which demonstrated a quality of life and survival benefit for certain subsets of patients with emphysema. While the outcomes of carefully selected patients are excellent, with proven benefits in both quality of life and overall survival, the volume of LVRS being performed remains low. The procedure is highly regulated in the United States and is only performed in Centers for Medicare and Medicaid Services (CMS) approved programs. Programs are required to follow the NETT selection criteria. The program at Columbia University Medical Center/New York Presbyterian Hospital remains active. Utilizing the NETT criteria, we continue to perform LVRS with no operative mortality and excellent long-term outcomes.
\end{abstract}

Keywords: Lung volume reduction surgery (LVRS); chronic obstructive pulmonary disease (COPD); National Emphysema Treatment Trial (NETT); emphysema

Submitted Mar 15, 2018. Accepted for publication May 17, 2018.

doi: $10.21037 /$ jtd.2018.05.135

View this article at: http://dx.doi.org/10.21037/jtd.2018.05.135

\section{Introduction}

Lung volume reduction surgery (LVRS) was first proposed by Otto Brantigan in the 1950's (1). His operations included staged bilateral thoracotomies with a clamp and sew method of volume reduction coupled with parasympathetic denervation of the lung. He reported a $19 \%$ operative mortality in a series of 26 patients. The procedure fell out of favor given the high mortality and unpredictable results.

The procedure was reinvigorated after Joel Cooper learned of LVRS in the early 1990's (2). His series of procedures led to widespread enthusiasm for the procedure, as well as considerable controversy (3). Likely due to misapplication of the procedure and resulting high mortality, the United States Medicare program halted payment for the procedure and determined the need for a randomized, controlled trial to prove the benefit of LVRS (4).

The National Emphysema Treatment Trial (NETT) trial was the resulting trial. The NETT trial first reported the outcomes of a high-risk cohort who had a very high mortality and were already known not to be good operative candidates $(3,4)$. The main results were then published which defined the subgroups who benefited in terms of mortality and quality of life (5). Long-term follow up was published which confirmed the durable benefit to patients with upper lobe predominate emphysema with high exercise tolerance (6).

Despite the incredible costs of this trial and the impressive and durable benefits shown, the volume of surgery remains low (7). At Columbia University Medical Center/New York Presbyterian Hospital (CUMC/NYP), 
Table 1 Baseline characteristics

\begin{tabular}{|c|c|}
\hline Baseline characteristics & Statistics $(\mathrm{N}=111)$ \\
\hline Age (years) & $63.1 \pm 6.8$ \\
\hline BMI $\left(\mathrm{kg} / \mathrm{m}^{2}\right)$ & $24.6 \pm 3.7$ \\
\hline \multicolumn{2}{|l|}{ Race, n (\%) } \\
\hline White & $102(91.9)$ \\
\hline Hispanic \& Black & $9(8.1)$ \\
\hline Sex (male), n (\%) & $50(45.0)$ \\
\hline \multicolumn{2}{|l|}{ Distribution of emphysema on CT, $\mathrm{n}(\%)$} \\
\hline Predominantly upper lobe & $111(100.0)$ \\
\hline Maximal workload (W) & $38.5 \pm 19.8$ \\
\hline 6MWT (feet) & $1,231.0 \pm 271.3$ \\
\hline $\begin{array}{l}\text { FEV1 after bronchodilator use (\% of predicted } \\
\text { value) }\end{array}$ & $26.1 \pm 6.6$ \\
\hline $\begin{array}{l}\text { FEV1 after bronchodilator use (absolute } \\
\text { value) }\end{array}$ & $0.7 \pm 0.2$ \\
\hline $\mathrm{RV}$ (\% of predicted value) & $211.6 \pm 42.2$ \\
\hline DLCO (\% of predicted value) & $29.1 \pm 7.4$ \\
\hline $\mathrm{PCO}_{2}(\mathrm{mmHg})$ & $40.4 \pm 6.1$ \\
\hline $\mathrm{PaO}_{2}(\mathrm{mmHg})$ & $67.6 \pm 9.3$ \\
\hline \multicolumn{2}{|l|}{ Type of surgery, n (\%) } \\
\hline Bilateral VATS & $98(88.3)$ \\
\hline Median sternotomy & $11(9.9)$ \\
\hline Right VATS & $2(1.8)$ \\
\hline 6-month mortality ( $\mathrm{N}=95$ eligible), $\mathrm{n}(\%)$ & $0(0)$ \\
\hline \multicolumn{2}{|l|}{ Discharge disposition ( $\mathrm{N}=111), \mathrm{n}(\%)$} \\
\hline Home & $101(91.0)$ \\
\hline Rehabilitation & $9(8.1)$ \\
\hline Inpatient acute & $1(0.9)$ \\
\hline Length of stay in ICU (days), median (IQR) & $2(1,3)$ \\
\hline $\begin{array}{l}\text { Length of stay in the hospital (days), median } \\
\text { (IQR) }\end{array}$ & $8(6,10)$ \\
\hline
\end{tabular}

we continue to perform LVRS utilizing the NETT criteria.

\section{Columbia results}

Our program began with the early days of the NETT

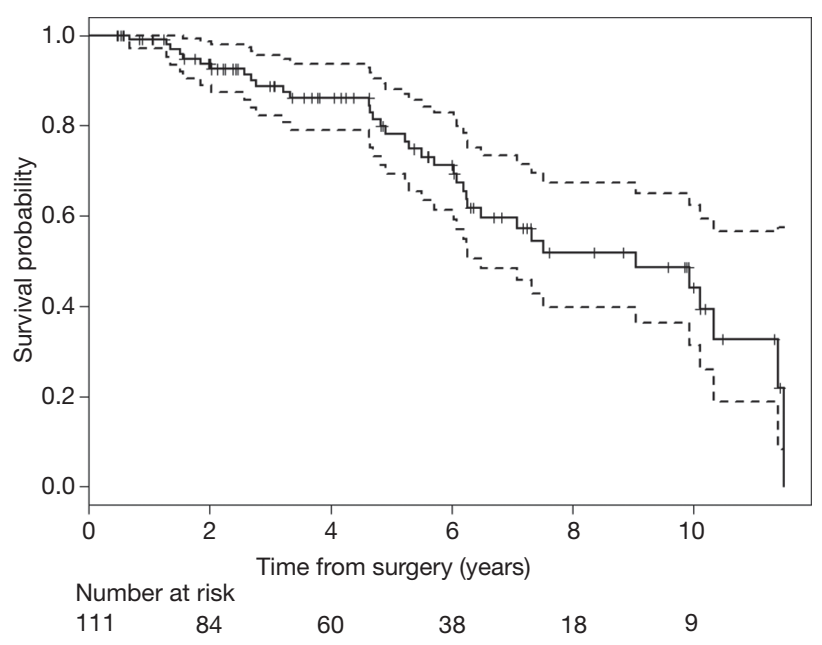

Figure 1 Kaplan-Meier survival curve (solid line) with the $95 \%$ confidence interval (dashed line).

trial and is Centers for Medicare and Medicaid Services (CMS) approved. It is approved by the IRB of CUMC. Our program has been in continuous operation since it was started in 2004.

We have reported our results at various intervals to demonstrate the excellent operative morbidity and mortality as well as the long-term outcomes $(7,8)$. The data presented here represent our experience through early 2017.

Patients with severe emphysema referred to our institution during this period were evaluated for LVRS using the selection criteria of NETT. All patients accepted for LVRS underwent preoperative pulmonary rehabilitation and were reevaluated after completing that program. All patients undergoing LVRS met NETT inclusion and exclusion criteria and CMS requirements as has been described elsewhere (5). Follow-up was performed at 6 months and then yearly.

Our surgical technique has been described elsewhere, but generally includes an epidural and bilateral VATS with buttressed staplers (7).

Since 2004, we have performed LVRS on 111 patients. Table 1 describes the baseline characteristics of our patient population. The average age was 63 years old and the cohort was $45.0 \%$ male, $87.2 \%$ of patients underwent a bilateral VATS procedure. The mean FEV1 and DLCO were $26 \%$ and $29 \%$ respectively.

Our 6-month operative mortality was $0 \%$. Most patients, $91 \%$, were discharged to home. The median length of ICU stay and hospital stay were 2 and 8 days respectively. Figure 1 
Table 2 Functional outcomes

\begin{tabular}{|c|c|c|c|}
\hline Functional outcomes & $\mathrm{n}$ & Mean $(95 \% \mathrm{Cl})$ & $P$ value \\
\hline \multicolumn{4}{|l|}{6 months } \\
\hline FEV1 (\% predicted) & 91 & $13.1(10.9,15.3)$ & $<0.001$ \\
\hline RV (\% predicted) & 90 & $-63.3(-71.2,-55.4)$ & $<0.001$ \\
\hline DLCO (\% predicted) & 89 & $5.0(3.5,6.5)$ & $<0.001$ \\
\hline 6MWT (feet) & 90 & $122.5(85.2,159.9)$ & $<0.001$ \\
\hline Maximal workload (W) & 87 & $12.0(9.4,14.6)$ & $<0.001$ \\
\hline Dyspnea index & 90 & $-1.6(-1.8,-1.3)$ & $<0.001$ \\
\hline \multicolumn{4}{|l|}{1 year } \\
\hline FEV1 (\% predicted) & 77 & $10.8(8.7,12.9)$ & $<0.001$ \\
\hline RV (\% predicted) & 77 & $-58.1(-66.0,-50.2)$ & $<0.001$ \\
\hline DLCO (\% predicted) & 77 & $5.2(3.4,6.9)$ & $<0.001$ \\
\hline 6MWT (feet) & 74 & $118.3(76.7,162.0)$ & $<0.001$ \\
\hline Maximal workload (W) & 70 & $11.0(7.8,14.3)$ & $<0.001$ \\
\hline Dyspnea index & 75 & $-1.6(-1.9,-1.4)$ & $<0.001$ \\
\hline \multicolumn{4}{|l|}{5 years } \\
\hline FEV1 (\%predicted) & 27 & $8.8(5.5,12.2)$ & $<0.0001$ \\
\hline RV (\% predicted) & 26 & $-81.1(-95.2,-66.9)$ & $<0.0001$ \\
\hline DLCO (\% predicted) & 27 & $4.0(1.1,6.9)$ & 0.0093 \\
\hline 6MWT (feet) & 27 & $-76.2(-196.8,44.4)$ & 0.2055 \\
\hline Maximal workload (W) & 23 & $7.8(3.1,12.6)$ & 0.0025 \\
\hline Dyspnea index & 34 & $-1.0(-1.5,-0.5)$ & 0.0003 \\
\hline
\end{tabular}

FEV1, forced expiratory volume in one second; RV, residual volume; DLCO, Diffusion Capacity for Carbon Monoxide of the Lung; 6MWT, 6-minute walk test.

Table 3 Survival outcomes

\begin{tabular}{lc}
\hline Parameters & Outcome \\
\hline $\mathrm{N}$ & 111 \\
No. of deaths & 36 \\
Median survival $(95 \% \mathrm{Cl})$, years & $9.05(6.26-11.4)$ \\
Survival, median $(95 \% \mathrm{Cl})$ & \\
1-year & $0.99(0.97-1.00)$ \\
2-year & $0.94(0.89-1.00)$ \\
5-year & $0.78(0.69-0.88)$ \\
\hline
\end{tabular}

shows Kaplan-Meier survival serve out to 10 years.

The functional outcomes over time are shown in Table 2. Values are expressed in absolute values of improvement, not the relative percent improvement. For example, the mean FEV1 improvement of $13 \%$ means the FEV1 went from $30 \%$ to $43 \%$, not a $13 \%$ relative improvement. Virtually all measured parameters are improved out to 5 years in our cohort. Sustained improvements are noted in the measured pulmonary function tests (PFT's). The 6-minute walk test remains improved until 5 years.

Table 3 shows our mortality data and Kaplan-Meier curve. Our 1-year survival remains $99 \%$ with a median survival of 9.05 years. Our 5 -year survival is $78 \%$.

\section{Discussion}

Columbia University Medical Center/New York Presbyterian Hospital has been a part of LVRS from the earliest days of its resurgence. We participated in the NETT trial and have participated in virtually all of the bronchoscopic LVRS trials. Despite our outstanding results and an enthusiastic group of pulmonary colleagues, we still are performing a low volume of LVRS given the large cohort who should theoretically be candidates for the procedure.

We have obtained these results by strictly following the NETT criteria. In addition, we are very careful to evaluate the degree of adhesions at the time of surgery. We have a low threshold to perform both sides in lateral decubitus position, as opposed to supine. This allows for safer lysis of adhesions. We also make a judgment at the time of surgery as to whether the degree of adhesions to areas of the lung that will remain after the surgery preclude doing one side. By judiciously avoiding any damage to the remaining lung, air leaks and associated complications can be avoided. We also make liberal use of Heimlich valves to allow for earlier discharges.

In summary, we are strong believers in LVRS and continue to perform stable volume of surgery with excellent outcomes and sustained functional improvement for this challenging subset of patients.

\section{Acknowledgements}

None. 


\section{Footnote}

Conflicts of Interest: The authors have no conflicts of interest to declare.

\section{References}

1. Brantigan OC, Mueller E, Kress MB. A surgical approach to pulmonary emphysema. Am Rev Respir Dis 1959;80:194-206.

2. Cooper JD. The History of Surgical Procedures for Emphysema. Ann Thorac Surg 1997;63:312-9.

3. Cooper JD, Trulock EP, Triantafillou AN, et al. Bilateral pneumectomy (volume reduction) for chronic obstructive pulmonary disease. J Thorac Cardiovasc Surg 1995;109:106-116; discussion 116-119.

4. National Emphysema Treatment Trial Research Group, Fishman A, Fessler H, et al. Patients at high risk of death

Cite this article as: Stanifer BP, Ginsburg ME. Lung volume reduction surgery in the post-National Emphysema Treatment Trial era. J Thorac Dis 2018;10(Suppl 23):S2744-S2747. doi: 10.21037/jtd.2018.05.135 after lung-volume-reduction surgery. N Engl J Med 2001;345:1075-83.

5. Fishman A, Martinez F, Naunheim K, et al. A randomized trial comparing lung-volume-reduction surgery with medical therapy for severe emphysema. $\mathrm{N}$ Engl J Med 2003;348:2059-73.

6. Naunheim KS, Wood DE, Mohsenifar Z, et al. Long-term follow-up of patients receiving lung-volume-reduction surgery versus medical therapy for severe emphysema by the National Emphysema Treatment Trial Research Group. Ann Thorac Surg 2006;82:431-43.

7. Ginsburg ME, Thomashow BM, Yip CK, et al. Lung volume reduction surgery using the NETT selection criteria. Ann Thorac Surg 2011;91:1556-60; discussion 1561.

8. Ginsburg ME, Thomashow BM, Bulman WA, et al. The safety, efficacy, and durability of lung-volume reduction surgery: A 10-year experience. J Thorac Cardiovasc Surg 2016;151:717-24. 